\title{
Análise da ação da quimioterapia fotodinâmica antimicrobiana (PACT) com Ftalocianina cloro-alumínio (FC-ClAl) sobre os microrganismos Pseudomonas aeruginosa (Gram -) e Staphylococcus aureus $($ Gram +$)$
}

\author{
Jessica Lucia Neves Bastos*, Márcia Nitschke, Nivaldo Antonio Parizotto
}

\begin{abstract}
Resumo Introdução: A grande incidência de bactérias patogênicas resistentes tem incentivado a busca de uma alternativa viável para a inativação satisfatóriadas mesmas. A quimioterapia fotodinâmica antimicrobiana (PACT) é uma alternativa já encontrada que tem apresentado resultados satisfatórios na eliminação de células indesejadas. A Ftalocianina, por sua vez, tem sido apontada como um fármaco fotossensível eficaz na eliminação de tecido tumoral e na potencialização do processo cicatricial de feridas. Entretanto, se fez necessário iniciar a realização de testes para averiguar se essa substância também apresenta eficácia na eliminação de células bacterianas, considerando que estas frequentemente ocorrem em ferimentos. Objetivo: Este trabalho objetivou analisar se há uma ação satisfatória da PACT com a Ftalocianina Cloro-Alumínio (FC-ClAl) na inativação de bactérias, e se esta possível ação está relacionada apenas à eficácia do fármaco utilizado ou se há interferência da metodologia envolvida. Métodos: Em biofilmes de $P$. aeruginosa e $S$. aureus realizou-se etapa única de aplicação da PACT/FC-ClAl com duas diferentes formulações. Foram feitas análises quantitativas através da contagem de UFC e medidas de absorbância em leitora de ELISA. A pré-lavagem da metodologia utilizada na PACT não mostrou ter interferência nos resultados finais dos experimentos. A redução de microrganismos nos grupos pós-lavagem só foi observada nos grupos experimentais com a $P$. aeruginosa que receberam os fármacos, apontando para uma ação da droga, e não da metodologia. Conclusão: Não houve diferenças estatísticas significativas entre os grupos experimentais com $S$. aureus. Foi possível também observar uma ação bactericida das substâncias testadas, encorajando a realização de análises mais detalhadas para averiguar se esse resultado se mantém com biofilmes mais maduros e se é mais eficaz com substâncias outras associadas à Ftalocianina Cloro-Alumínio.
\end{abstract}

Palavras-chave Ftalocianina cloro-alumínio, PACT, Microrganismo, Ftalocianina.

\section{Analysis of photodynamic antimicrobial chemotherapy (PACT) action with Chloro-Aluminum Phthalocyanine (Pc-ClAl) on Pseudomonas aeruginosa (Gram-) and Staphylococcus aureus (Gram +) microorganisms}

Abstract Introduction: The high incidence of resistant bacteria has encouraged the search for a viable alternative to satisfactory inactivation of these pathogens. The photodynamic antimicrobial chemotherapy (PACT) is an alternative already found that has shown satisfactory results to eliminate unwelcome cells. The Phthalocyanine, in turn, has been identified as a photosensitive drug effective for the tumor tissue elimination and the enhancement of the wounds healing process. Currently, it became necessary start some tests to check if this substance also has efficacy in the bacterial cells elimination, once these microorganisms often occur on open wounds. Objective: This study aimed to analyze whether there is a satisfactory action of PACT with Chloro-Aluminum Phthalocyanine ( $F C$-ClAl) in the bacteria inactivation, and if its possible action is related only to the effectiveness of the drug used or if there is interference of the methodology involved. Methods: In biofilms of P. aeruginosa and S. aureus was carried out a single application of PACT/FC-ClAl with two different formulations. Quantitative analyzes were performed by counting $C F U$ and absorbance measurements in ELISA reader. The results showed that the pre-washingused in the PACT methodology do not interfered in the final results of the experiments. The reduction of microorganisms in groups after washing was only observed in the experimental groups with P. aeruginosa that received the drugs, pointing to a drug action, and not to an interference of the methodology. Conclusion: There were no statistically significant differences between experimental groups with $S$. aureus. It was also possible to observe a bactericidal action of the used substance, encouraging more detailed analyzes to determine if this result holds with more mature biofilms and if it is more effective with other substances associated with Chloro-Aluminum Phthalocyanine.

Keywords Ftalocianina cloro-alumínio, PACT, Microrganismo, Ftalocianina.

*e-mail: jessica.bastos@gmail.com

Recebido: 28/12/2012 / Aceito: 31/03/2013 


\section{Introdução}

Muito se tem pesquisado ultimamente sobre tratamentos alternativos para a eliminação satisfatória de microrganismos, tanto para casos de contaminação de materiais inertes, quanto de alimentos e tecidos biológicos (Karska-Wysocki et al., 2010; Ramesh et al., 2003; Shieh et al., 2009). A grande incidência de bactérias cada vez mais resistentes às drogas existentes tem incentivado pesquisadores do mundo inteiro a buscar uma alternativa viável para a inativação desses agentes patogênicos. Uma alternativa já encontrada é a chamada quimioterapia fotodinâmica antimicrobiana (PACT) a qual, até o presente momento, tem apresentado resultados satisfatórios não só na eliminação de células indesejadas (bacterianas), como também na prevenção de desenvolvimento de resistência por parte do tecido/célula tratado (Denis et al., 2011; Rajesh et al., 2011), além de permitir uma aplicação tópica sem comprometimento de outras estruturas sistêmicas, o que evita a ocorrência de maiores danos ao organismo/material contaminado.

A quimioterapia fotodinâmica antimicrobiana (PACT) é um método de tratamento para desinfecção de superfícies/tecidos, cuja metodologia envolve o uso de uma droga fotossensível (FS) associada à ativação luminosa através da luz laser ou LED. Seu mecanismo de ação está relacionado, em presença da luz, à produção de oxigênio tóxico (singlete / ROS) e radicais livres, os quais levam à destruição do tecido alvo por um mecanismo de necrose e/ou apoptose (Gomes et al., 2005; Zhu e Zheng, 2008). A toxicidade dessas substâncias está relacionada com a dose aplicada, via de administração, absorção, seletividade e biodistribuição do FS, assim como com o tipo de luz, irradiância, disponibilidade de oxigênio na célula, e intervalo entre a administração do fotossensibilizador (FS) no tecido alvo e a aplicação da luz (Wiedmann e Caca, 2004; Allison e Sibata, 2008).

A Ftalocianina cloro-alumínio (FC-ClAl) é um fármaco fotossensível classificado como de segunda geração, que apresenta grande lipofilicidade, ou seja, se liga facilmente à membrana plasmática, microssomos e mitocôndrias (Rosenthal, 1991). Sua ação sobre a proliferação fibroblástica foi demonstrada no trabalho de Silva et al. (2004), onde a Terapia Fotodinâmica (PDT) com FC-ClAl $(685 \mathrm{~nm})$ em feridas de ratos resultaram em um aumento da re-epitelização e maior presença de colágeno no sítio de lesão, sem evidências de que esse tipo de tratamento tenha causado qualquer dano ao processo de cicatrização. Desta forma, em face dos resultados positivos quanto à utilização desse fármaco para o reparo tecidual, questiona-se qual seria a ação da $\mathrm{FC}-\mathrm{ClAl}$ ao se ter, na lesão, a presença de microrganismos patogênicos. A ação inibitória dessa substância sobre as bactérias comumente presentes em úlceras abertas representaria uma grande vantagem, pois se teria, ao mesmo tempo, a desinfecção da lesão associada ao estímulo da proliferação fibroblástica.

Em geral, a metodologia da PACT envolve um primeiro contato celular/tecidual com o fármaco fotossensível por um período de tempo que pode variar de 30 a 60 minutos, seguindo-se de uma lavagem das amostras para uma posterior ativação pelo laser/LED. A aplicação dessa metodologia levou ao questionamento se essa lavagem pré-irradiação não causaria já algum dano às células envolvidas ao se usar a Ftalocianina cloro-alumínio como fármaco fotossensível, ocasionando, p.e, uma redução prévia no número de microrganismos, mesmo antes da ativação da droga pela luz. Desta forma, uma análise da condição dos microrganismos na pré e na pós-lavagem seria de grande utilidade para verificar quando se inicia a possível ação satisfatória do uso da $\mathrm{PACT} / \mathrm{FC}-\mathrm{ClAl}$ na eliminação de bactérias.

O presente trabalho objetivou analisar se há uma possível ação satisfatória da quimioterapia fotodinâmica antimicrobiana (PACT) com a Ftalocianina CloroAlumínio e se esta está relacionada apenas à ação do fármaco utilizado ou se há interferência da lavagem préirradiação das amostras, utilizada nessa metodologia.

\section{Métodos}

\section{Microrganismos}

Cepas de campo de Staphylococcus aureus e Pseudomonas aeruginosa, espécies essas mais frequentemente encontradas em úlceras dérmicas contaminadas, foram selecionadas para os testes da metodologia da quimioterapia fotodinâmica antimicrobiana (PACT) com Ftalocianina CloroAlumínio ( $\mathrm{FC}-\mathrm{ClAl})$, associada à irradiação laser. As culturas foram obtidas da Faculdade de Ciências Farmacêuticas - UNESP/AQA, em meio líquido BHI, previamente inoculadas e incubadas por 24 horas. A partir destas, foram feitos estoques em tubos ágar inclinado, inoculando-se uma alça de cada cultura em tubos contendo Muller Hinton ágar. Após um período de incubação de 24 horas a $37^{\circ} \mathrm{C}$, as culturas foram armazenadas em geladeira a $4{ }^{\circ} \mathrm{C}$ para utilização por um período de 1 mês, sendo substituídas por novos estoques a partir de culturas congeladas $\left(-20^{\circ} \mathrm{C}\right)$, também preparadas e estocadas a partir das culturas em meio líquido BHI previamente obtidas.

\section{Fármacos}

Duas formulações diferentes contendo a Ftalocianina Cloro-Alumínio (uma aniônica e outra catiônica) foram 
utilizadas para inativação de microrganismos, todas elas adquiridas do Departamento de Química - FFCLRP/ USP-RP, com o Grupo de Fotobiologia e Fotomedicina, sob responsabilidade do Prof. Dr. Antônio Cláudio Tedesco. A diluição das amostras, cuja concentração inicial era de $38 \mu \mathrm{mol} / \mathrm{mL}$, foi realizada com água de Mili-Q estéril para uma concentração final desejada de $5 \mu \mathrm{mol} / \mathrm{mL}$, a qual havia mostrado, em testes piloto, ser a mais eficaz para a eliminação bacteriana. As alterações químicas na formulação catiônica foram realizadas com base no potencial zeta da superfície polimérica da mesma, a qual de negativa passou a se comportar com potencial resultante positivo.

Considerando que a Ftalocianina é uma substância que tende a se agregar facilmente, impossibilitando, desta forma, a sua fotoativação, as formulações utilizadas foram nano estruturadas com o tensoativo Poloxamer, diluído em óleo Miglyol 812, aumentando assim seu perfil de diluição e impedindo a agregação entre suas moléculas.

\section{Irradiação laser}

As aplicações laser foram realizadas com comprimento de onda de $670 \mathrm{~nm}$ (vermelho), com doses de $35 \mathrm{~J} / \mathrm{cm}^{2}$, $\mathrm{P}=100 \mathrm{~mW}$. O aparelho utilizado foi um protótipo da DMC - Equipamentos, chamado FisioLase, cedido para uso em pesquisas científicas do laboratório de Eletrotermofototerapia - UFSCar.

\section{Métodos de análise}

Após as aplicações da PACT, a inoculação de $P$. aeruginosa e $S$. aureus em placas contendo Müller Hinton Ágar foi realizada através do método da gota, por 24 horas, para posterior contagem das unidades formadoras de colônias (UFC). Para tanto, retirou-se amostras de $1 \mathrm{~mL}$ de cada poço da placa de 24 poços, as quais foram submetidas a diluições seriadas de $10^{-1}$ até $10^{-9}$. Posteriormente a esse processo, foram retiradas gotas de $15 \mu \mathrm{L}$ referentes a cada diluição, depositando-as na placa e incubando-as a $37^{\circ} \mathrm{C}$ por 24 horas para contagem final das colônias nas gotas que apresentavam de 5 a 50 UFC. A determinação do número de células viáveis foi feita através da média do número de colônias multiplicada pela diluição, resultando desta forma, no número de UFC por mililitro de solução.

A quantificação dos microrganismos foi realizada também através de um ensaio colorimétrico sensível e reprodutível de proliferação. Este ensaio consistiu no acréscimo ao meio de cultura (adaptado para microplaca de 96 poços) de uma solução contendo MTT, 3-(4,5-dimethylthiazol-2-yl)-2,5-difenil brometo de tetrazólio. Ao ser veiculado em solução salina, o MTT é solúvel em água e apresenta uma coloração amarela. Essa substância, quando incorporada por células viáveis, tem a forma estrutural do anel de seu componente tetrazólio quebrada pelas enzimas dehidrogenases mitocondriais, dando origem a cristais insolúveis de formazina na coloração azul escuro.

O MTT foi diluído em água destilada estéril (pH 7.2) de maneira a se obter uma concentração final de $0,1 \%$. Dez microlitros $(10 \mu \mathrm{L})$ dessa solução foram adicionados a cada poço da microplaca, após serem submetidos aos tratamentos anteriormente descritos. Após 8 horas de incubação a $37^{\circ} \mathrm{C}$, a absorbância foi medida em leitora de microplaca da Thermoplate $(630 \mathrm{~nm})$.

\section{Grupos experimentais}

O experimento consistiu dos seguintes grupos: Controle (C) - grupos que não foram submetidos a nenhum tratamento; Formulação fármaco fotossensível (FFFS) - grupos tratados com a Ftalocianina CloroAlumínio (FC-ClAl) aniônica, associada à irradiação laser; Formulação catiônica fármaco fotossensível (FCFFS) - grupos tratados com a Ftalocianina CloroAlumínio (FC-ClAl) com carga positiva, associada à irradiação laser; Controle laser (CL) - grupos tratados apenas com a irradiação laser $35 \mathrm{~J} / \mathrm{cm}^{2}$.

\section{Procedimentos experimentais}

Duzentos microlitros de uma solução com densidade óptica inicial (DO) de 0.190A (P. aeruginosa) e $1,150 \mathrm{~A}$ (S. aureus) foi semeado em microplacas de 24 poços contendo cada um 1,0 $\mathrm{mL}$ de caldo Müller Hinton. Para análises de absorbância com MTT, foram utilizadas microplacas de 96 poços contendo $180 \mu \mathrm{L}$ do mesmo meio de cultura e $20 \mu \mathrm{L}$ de microrganismos com mesma turbidez inicial tanto para $P$. aeruginosa quanto $S$. aureus. Ambos os cultivos foram realizados 24 horas antes do início dos tratamentos para assegurar a formação de biofilme maduro nas amostras.

\section{Grupos submetidos à PACT - Ftalocianina cloro-Alumínio}

Antes da aplicação dos fármacos, retirou-se $75 \%$ do meio de cultivo, seguindo-se a aplicação ao restante nos poços das 2 formulações, as quais tiveram um tempo de 45 minutos de ação em contato com as amostras, em meio escuro. Seguiu-se com acréscimo de $10 \mu \mathrm{L}$ de MTT aos grupos experimentais das microplacas de 96 poços para posterior análise da absorbância das amostras pré-lavagem. Para a análise dos grupos pós-lavagem seguiu-se os mesmos procedimentos anteriormente descritos, procedendo-se, após o tempo de contato dos fármacos com as amostras, a lavagem dos poços com tampão $\mathrm{PBS}$, para posterior fotoativação laser. Após 30 minutos de descanso das amostras, 
acrescentou-se o MTT para análise de absorbância. As microplacas de 24 poços, após os 30 minutos de descanso da amostra, foram submetidas a banho de ultrassom (US) por 10 minutos, visando soltar os microrganismos aderidos, seguindo-se da inoculação dos resíduos ("pellets" bacterianos) em placa de Petri contendo Müeller Hinton Agar (método da gota), com posterior contagem das UFC.

\section{Grupos submetidos à terapia laser de baixa intensidade (LLLT)}

A aplicação da LLLT foi realizada nas amostras de biofilme maduro de ambos os microrganismos após a lavagem dos poços com tampão - PBS, seguida da aplicação de $1 \mathrm{~mL}$ (microplaca de 24 poços) e $180 \mu \mathrm{L}$ (microplaca de 96 poços) de PBS para as irradiações laser $-670 \mathrm{~nm}, 35 \mathrm{~J} / \mathrm{cm}^{2}, 100 \mathrm{~mW}$. Um intervalo de 30 minutos de repouso pós-irradiação foi observado antes da submissão das placas a banho de ultrassom (US) por 10 minutos, para soltura dos microrganismos aderidos nas microplacas de 24 poços, seguido da inoculação dos resíduos ("pellets" bacterianos) em placa de Petri contendo Müeller Hinton Agar (método da gota),com posterior contagem das UFC. Houve acréscimo de $10 \mu \mathrm{L}$ de MTT nos grupos experimentais das microplacas de 96 poços após os 30 minutos de repouso das amostras, visando posterior análise da absorbância das amostras.

\section{Análise estatística}

Os dados quantitativos obtidos foram comparados através de análise de variância (ANOVA) com nível de confiança de $95 \%$, utilizando o software Origin v.8 (Origin Lab Corporation).

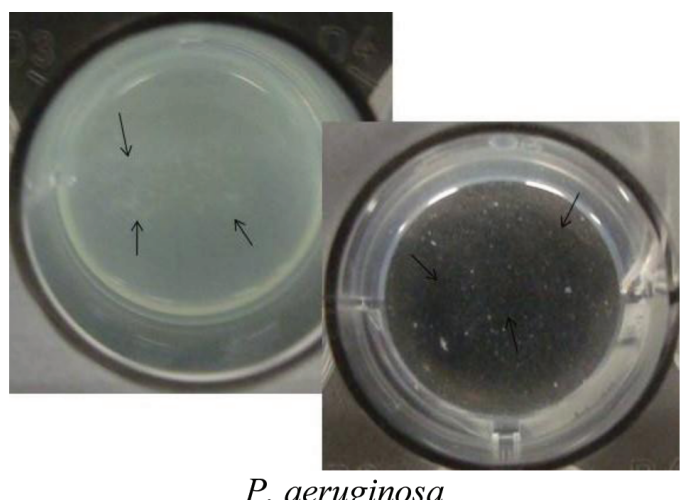

P. aeruginosa

\section{Resultados}

As Tabelas 1 a 8 trazem os resultados quantitativos obtidos após a realização dos procedimentos experimentais propostos. A Figura 1 ilustra o aspecto macroscópico das amostras após a aplicação da PACT com Ftalocianina cloro - alumínio catiônica, e a Figura 2 traz representado em forma de gráfico de barras, as médias e desvios padrão adquiridas.

\section{Discussão}

Durante os procedimentos experimentais em microplacas de 24 poços algumas alterações nos biofilmes bacterianos formados no fundo de cada poço foram macroscopicamente observadas, apresentando estes, pontos de descontinuidade mesmo antes de se ter a fotoativação do fármaco em questão. Tais alterações foram principalmente visualizadas na formulação catiônica.

A Figura 1 mostra os pontos de descontinuidade nos biofilmes microbianos, observados previamente à fotoativação dos fármacos em questão. Essas alterações podem ter sido consequência de danos à sua estrutura do biofilme, resultando em uma soltura com posterior aspiração do mesmo durante o processo de lavagem que antecede a aplicação do laser. A causa desse possível dano ao biofilme estaria relacionada à ocorrência de "poros" resultantes da aplicação de uma carga positiva muito intensa, encontrada na formulação catiônica. Vale ressaltar que essas alterações macroscópicas foram visualizadas apenas após o tempo de aplicação de 45 minutos da formulação catiônica. A formulação contendo apenas o fármaco (FFFS) não provocou alterações significativas a olho nu.

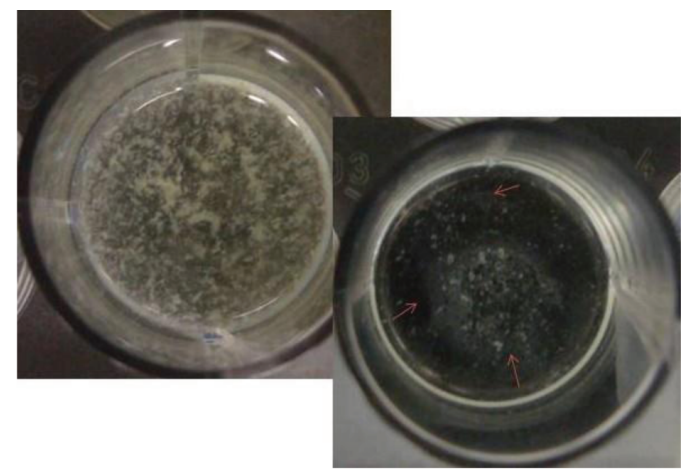

S. aureus

Figura 1. Nas fotos da esquerda, grupo experimental com P. aeruginosa, e nas fotos da direita, com S. aureus, as setas apontam para uma intensa aglutinação/granulação de ambos biofilmes microbianos após 45 minutos de contato com a formulação FCFFS.

Figure 1. In the pictures on the left, experimental group with P. aeruginosa, and in the pictures on the right, with S. aureus, arrows point to an intense bonding/granulation of both microbial biofilms after 45 minutes of contact with FCFFS formulations. 
Após a realização das medidas de absorbância dos grupos experimentais, calcularam-se as médias e desvios padrão de cada grupo, comparando-as para a verificação de eventuais diferenças de redução microbiana de cada fármaco utilizado.

Nas Tabelas 1 e 2 temos os valores médios de absorbância e número de UFC dos grupos experimentais tanto de $P$. aeruginosa quanto $S$. aureus. Na Tabela 1 pode-se observar uma redução na densidade de células viáveis principalmente quando se compara o grupo controle laser (CL) ao grupo que foi fotoativado após receber a formulação catiônica (FCFFS); já a redução observada em relação apenas ao uso da Ftalocianina irradiada com laser (FFFS) não foi tão significativa, apontando para uma eficácia reduzida dessa substância para a inativação da P. aeruginosa. Ainda na Tabela 1,

Tabela 1. Média e desvio padrão dos grupos experimentais com $P$. aeruginosairradiados com laser $35 \mathrm{~J} / \mathrm{cm}^{2}$. CL: grupo controle laser; FFFS: formulação com fármaco fotossensível; FCFFS: formulação catiônica com fármaco fotossensível.

Table 1. Mean and standard deviation of the experimental groups with P. aeruginosa irradiated with laser $35 \mathrm{~J} / \mathrm{cm}^{2}$. CL: laser control group; FFFS: photosensitive drug formulation; FCFFS: cationic formulation with photosensitive drug.

\begin{tabular}{|c|c|c|c|c|c|}
\hline \multicolumn{6}{|c|}{ Grupos $P$. aeruginosa } \\
\hline & Grupos & $\begin{array}{l}\text { Abs média } \\
630 \mathrm{~nm}\end{array}$ & Desvio padrão & $\begin{array}{l}\text { Log UFC/mL } \\
\text { (média) }\end{array}$ & Desvio padrão \\
\hline \multirow{3}{*}{ LASER 35} & $\mathbf{C L}$ & 0,712 & 0,07 & 7,7 & 0,16 \\
\hline & FFFS & 0,615 & 0,08 & 7,3 & 0,07 \\
\hline & FCFFS & 0,231 & 0,07 & 6,05 & 0,07 \\
\hline
\end{tabular}

Tabela 2. Média e desvio padrão dos grupos experimentais com $S$. aureus irradiados com laser $35 \mathrm{~J} / \mathrm{cm}^{2}$. CL: grupo controle laser; FFFS: formulação com fármaco fotossensível; FCFFS: formulação catiônica com fármaco fotossensível.

Table 2. Mean and standard deviation of the experimental groups with S. aureus irradiated with laser $35 \mathrm{~J} / \mathrm{cm}^{2}$. CL: laser control group; FFFS: photosensitive drug formulation; FCFFS: cationic formulation with photosensitive drug.

\begin{tabular}{|c|c|c|c|c|c|}
\hline \multicolumn{6}{|c|}{ Grupos S. aureus } \\
\hline & Grupos & $\begin{array}{l}\text { Abs média } \\
630 \mathrm{~nm}\end{array}$ & Desvio padrão & $\begin{array}{c}\text { Log UFC/mL } \\
\text { (média) }\end{array}$ & Desvio padrão \\
\hline \multirow{3}{*}{ LASER 35} & $\mathbf{C L}$ & 2,701 & 0,04 & 8,3 & 0,04 \\
\hline & FFFS & 2,576 & 0,24 & 7,8 & 0,11 \\
\hline & FCFFS & 1,598 & 0,27 & 7,1 & 0,12 \\
\hline
\end{tabular}

Tabela 3. Média e desvio padrão dos grupos experimentais pré e pós-lavagem dos poços da microplaca de 96 poços com $P$. aeruginosa. C: grupo controle; FFFS: formulação com fármaco fotossensível; FCFFS: formulação catiônica com fármaco fotossensível.

Table 3. Mean and standard deviation of the experimental groups with P. aeruginosa before and after washing the wells of 96-well microplate. C: control group; FFFS: photosensitive drug formulation; FCFFS: cationic formulation with photosensitive drug.

\begin{tabular}{llll}
\hline & Grupos $\boldsymbol{P}$ aeruginosa & & \multicolumn{1}{c}{ FFFS } \\
\hline Abs média à $630 \mathrm{~nm}$ (pré-lavagem) & C & 1,105 & 1,022 \\
Desvio padrão & 1,335 & 0,14 & 0,23 \\
Abs média à $630 \mathrm{~nm}$ (pós-lavagem) & 0,22 & 0,647 & 0,415 \\
Desvio padrão & 1,254 & 0,08 & 0,06 \\
\hline
\end{tabular}

Tabela 4. Média e desvio padrão dos grupos experimentais pré e pós-lavagem dos poços da microplaca de 96 poços com $S$. aureus. C: grupo controle; FFFS: formulação com fármaco fotossensível; FCFFS: formulação catiônica com fármaco fotossensível.

Table 4. Mean and standard deviation of the experimental groups with S. aureus before and after washing the wells of 96-well microplate. C: control group; FFFS: photosensitive drug formulation; FCFFS: cationic formulation with photosensitive drug.

\begin{tabular}{llll}
\hline & Grupos $\boldsymbol{S}$. aureus & & \multicolumn{2}{c}{ FFFS } & FCFFS \\
\hline Abs média à $630 \mathrm{~nm}$ (pré-lavagem) & C & 2,574 & 1,571 \\
Desvio padrão & 2,553 & 0,24 & 0,64 \\
Abs média à $630 \mathrm{~nm}$ (pós-lavagem) & 0,25 & 2,584 & 1,550 \\
Desvio padrão & 2,579 & 0,28 & 0,12 \\
\hline
\end{tabular}


Tabela 5. Comparação entre os grupos pré e pós-lavagem através do teste de Fisher - P. aeruginosa.

Table 5. Comparison between the groups pre and post-wash through the Fisher test $-P$. aeruginosa.

\begin{tabular}{cccc}
\hline \multicolumn{4}{c}{ Pós-lavagem } \\
\hline Pré-lavagem & $\mathbf{C}$ & FFFS & FCFFS \\
\hline C & 0 & 1 & 1 \\
FFFS & 1 & 1 & 1 \\
FCFFS & 1 & 1 & 1 \\
\hline
\end{tabular}

0 - diferença estatística não significativa. 1 - diferença estatística significativa.

Tabela 6. Comparação entre os grupos de laser $35 \mathrm{~J} / \mathrm{cm}^{2}$ e controle pós-lavagem através do teste de Fisher - $P$. aeruginosa.

Table 6. Comparison between laser $35 \mathrm{~J} / \mathrm{cm}^{2}$ groups and control post-wash groups using the Fisher test - P. aeruginosa.

\begin{tabular}{cccc}
\hline \multicolumn{4}{c}{ Pós-lavagem } \\
\hline LAER 35 & C & FFFS & FCFFS \\
\hline C & 0 & 0 & $Q$ \\
FFFS & 0 & 0 & $Q$ \\
FCFFS & 1 & 1 & 1 \\
\hline
\end{tabular}

0 - diferença estatística não significativa. 1 - diferença estatística significativa. $Q$ - ausência de redução de microrganismos em relação ao grupo pós-lavagem.

em relação à contagem de UFC, que mostra o número de células não apenas viáveis, mas também cultiváveis, a redução observada segue os padrões obtidos na medida de absorbância, onde a substância mais eficaz, em relação ao grupo controle laser, foi associada a uma carga catiônica. Este resultado enfatiza mais uma vez a real vantagem de se utilizar a Ftalocianina Cloro-Alumínio com carga positiva quando se deseja uma inativação de microrganismos Gram [-] como a Pseudomonas aeruginosa.

A Tabela 2 mostra os valores obtidos de absorbância e contagem do número de colônias após aplicação dos tratamentos em biofilmes de $S$. aureus, tanto com apenas irradiação laser quanto com a Ftalocianina fotoativada. Os resultados apontam para um comportamento semelhante desse microrganismo ao obtido com a $P$. aeruginosa, onde a substância mais eficaz para uma ação antimicrobiana foi a formulação com caráter catiônico (FCFFS), mesmo a redução tendo sido menor, menos significativa.

Entre os grupos pré e pós-lavagem (Tabelas 3 e 4), as medidas de absorbância apontam para uma redução no número de microrganismos em alguns grupos experimentais, mostrando uma possível interferência da metodologia utilizada na PACT para determinar, mesmo antes da fotoativação laser, uma redução na quantidade de microrganismos nas amostras utilizadas. A Tabela 3 traz os valores obtidos após aplicação dos fotossensibilizadores nos grupos com $P$. aeruginosa, onde se pode observar que a redução obtida na densidade de microrganismos após
Tabela 7. Comparação entre os grupos controles pré e pós-lavagem através do teste de Fisher - S. aureus.

Table 7. Comparison between the groups pre and post-wash through the Fisher test - S. aureus.

\begin{tabular}{cccc}
\hline \multicolumn{4}{c}{ Pós-lavagem } \\
\hline Pré-lavagem & C & FFFS & FCFFS \\
\hline C & 0 & 0 & 1 \\
FFFS & 0 & 0 & 1 \\
FCFFS & 1 & 1 & 0 \\
\hline
\end{tabular}

0 - diferença estatística não significativa. 1 - diferença estatística significativa.

Tabela 8. Comparação entre os grupos de laser $35 \mathrm{~J} / \mathrm{cm}^{2} \mathrm{e}$ controle pós-lavagem através do teste de Fisher - S. aureus.

Table 8. Comparison between laser $35 \mathrm{~J} / \mathrm{cm}^{2}$ groups and control post-wash groups using the Fisher test - S. aureus.

\begin{tabular}{cccc}
\hline \multicolumn{4}{c}{ Pós-lavagem } \\
\hline LAER 35 & C & FFFS & FCFFS \\
\hline C & 0 & 0 & $Q$ \\
FFFS & 0 & 0 & $Q$ \\
FCFFS & 1 & 1 & 0 \\
\hline
\end{tabular}

0 - diferença estatística não significativa. 1 - diferença estatística significativa. $Q$ - ausência de redução de microrganismos em relação ao grupo pós-lavagem.

a aplicação do fármaco, por 45 minutos, seguida de lavagem dos poços na preparação das amostras para posterior ativação laser, foi bastante elevada, sendo essa redução considerada como estatisticamente significativa (Tabela 5) para os grupos FFFS e FCFFS. Esses dados, porém, não invalidam a técnica para a realização da $\mathrm{PACT} / \mathrm{FC}-\mathrm{ClAl}$ uma vez que, em relação ao grupo controle, não foi observada uma redução significativa (Tabela 5) nos grupos pré e pós-lavagem. A técnica que envolve a pré-lavagem das amostras antes da fotoativação do fármaco só seria considerada inadequada caso determinasse, já no grupo controle, uma redução significativa na densidade de microrganismos, o que apontaria para uma ação mecânica de soltura do biofilme. Esses dados podem indicar uma ação prévia dos fármacos utilizados na possível ocorrência de danos à estrutura dos biofilmes de $P$. aeruginosa, fato esse que causaria um desprendimento de microrganismos, os quais teriam sido aspirados durante o processo de lavagem pré fotoativação.

Em relação à $S$. aureus as diferenças estatísticas significativas não foram muito evidentes ao se comparar os grupos pré e pós-lavagem (Tabela 4). A formulação que mais apresentou diferenças relevantes ao se comparar os subgrupos em questão foi, mais uma vez, a catiônica (Tabela 7). Tais dados permitem deduzir que, nesse caso, a droga utilizada não foi capaz de determinar a morte das bactérias sem que houvesse a aplicação da luz. As diferenças entre os subgrupos visualizadas na solução catiônica apontam para uma 
possível ação da carga positiva na ruptura do biofilme com consequente liberação dos microrganismos aderidos à superfície, os quais foram aspirados durante o processo de lavagem, causando uma redução no número de bactérias.

As Tabelas 6 e 8 trazem uma comparação estatística entre os grupos tratados com PACT/FC-ClAl (FFFS e FCFFS) e laser $35 \mathrm{~J} / \mathrm{cm}^{2}(\mathrm{C})$, e os pós-lavagem. Em relação à $P$. aeruginosa (Tabela 6), apenas o subgrupo que recebeu a formulação catiônica apresentou uma diferença estatística significativa quando comparado aos subgrupos do grupo pós-lavagem. Quando se comparam os 2 subgrupos que receberam a formulação catiônica (FCFFS), nota-se que a fotoativação determinou uma redução ainda maior no número de microrganismos, apontando para uma possível otimização do processo de eliminação bacteriana quando se tem a irradiação laser do fármaco em questão.

Na Tabela 8, os resultados da comparação estatística entre os grupos experimentais com a $S$. aureus. mostram um comportamento semelhante ao observado entre os grupos experimentais com $P$. aeruginosa, onde se obteve uma redução estatisticamente significativa apenas nos subgrupos que receberam o fármaco com carga positiva, quando comparados ao grupo pós-lavagem. Porém, ao contrário do obtido com a $P$. aeruginosa, não se observa uma redução ainda maior na densidade de microrganismos ao se ter a fotoativação da formulação catiônica. Esse dado aponta para uma eficácia menor desse fármaco para a eliminação de $S$. aureus.

$\mathrm{Na}$ Figura 2 têm-se representado em forma de gráfico, os valores de média e desvio padrão obtidos através da medida de absorbância após aplicação do MTT, no final de todo o procedimento experimental com a $P$. aeruginosa. Nele pode-se notar facilmente uma redução significativa no número de microrganismo nos subgrupos FFFS e FCFFS dos grupos pós-lavagem e irradiados com laser $35 \mathrm{~J} / \mathrm{cm}^{2}$, principalmente após a aplicação da PACT com a formulação catiônica, na qual se obteve também uma redução significativa em relação aos grupos controles pré e pós-lavagem. A redução visualizada para o grupo com apenas a Ftalocianina (FFFS) não foi tão significativa quanto à observada no grupo catiônico após a irradiação com laser vermelho, quando se compara ao subgrupo que recebeu apenas o laser $35 \mathrm{~J} / \mathrm{cm}^{2}$ como tratamento (subgrupo C do grupo laser $35 \mathrm{~J} / \mathrm{cm}^{2}$ ).

Nesta mesma Figura 2, em relação ao grupo pré-lavagem, observa-se também uma leve redução no número de microrganismos nos subgrupos experimentais após exposição às drogas, sendo ela ainda maior no subgrupo que recebeu fármaco com carga invertida, indicando que há uma ação deste não apenas para determinar uma soltura do biofilme bacteriano, mas também para inativar os microrganismos envolvidos, mesmo antes de se realizar a lavagem e fotoativação das amostras. Pode-se observar também em relação a $P$. aeruginosa que, com exceção do grupo controle, a redução no grupo pós-lavagem é maior do que a do grupo prélavagem devido a uma possível associação entre a morte prévia dos microrganismos com uma eventual soltura e posterior aspiração e eliminação daquelas bactérias que permaneceram vivas nos poços, mesmo após terem sido expostas aos fármacos por 45 minutos. Em relação aos grupos com laser, percebe-se mais uma vez maior redução ao se associar a fotoativação com as formulações catiônicas. As reduções obtidas
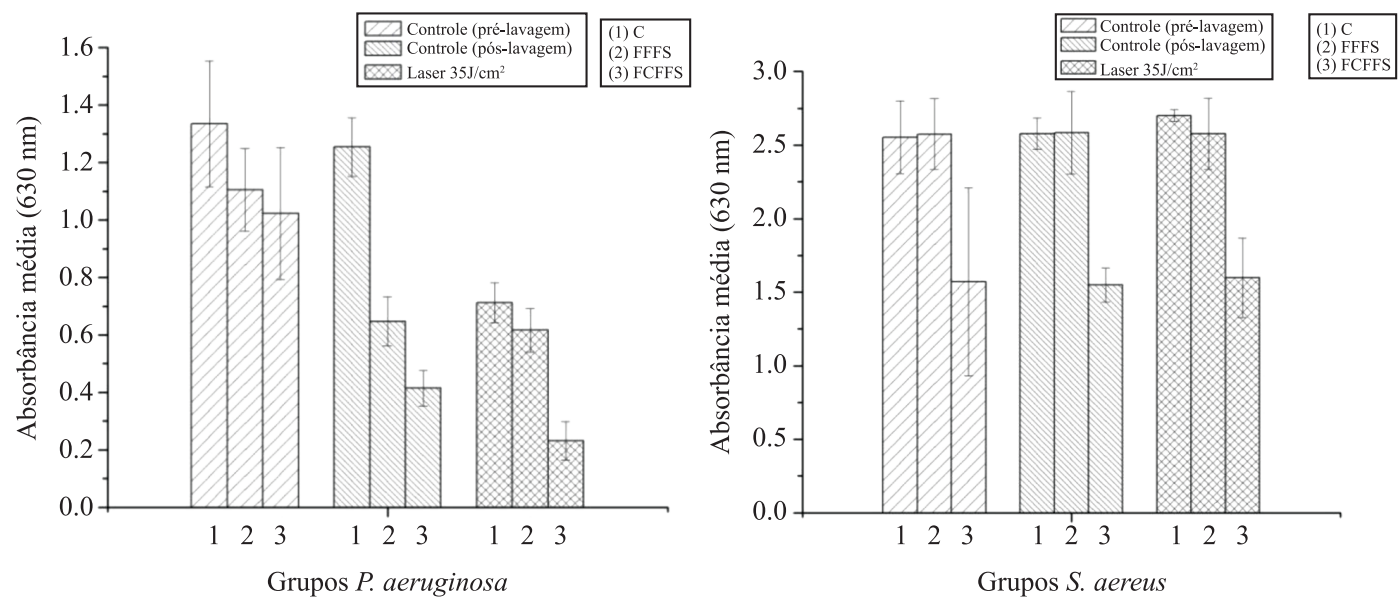

Figura 2. Gráfico com as médias e desvios padrão das medidas de absorbância referente aos grupos experimentais com $P$. aeruginosae $S$. aureus Figure 2. Graphic with means and standard deviations of absorbance measurements regarding the experimental groups with P. aeruginosa e S. aureus. 
apenas com a utilização da Ftalocianina (FFFS) fotoativada apresentaram uma significância menor.

Em relação aos grupos com $S$. aureus observa-se, na Figura 2, um comportamento que difere do obtido com a $P$. aeruginosa. Esse microrganismo mostrou uma sensibilidade menor tanto à $\mathrm{PACT} / \mathrm{FC}-\mathrm{ClAl}$ quanto ao laser vermelho somente. Nessa figura observa-se que a única substância capaz de determinar uma redução significativa no número de células bacterianas em todos os grupos foi a formulação catiônica (FCFFS), a qual apresentou também grande eficácia nos grupos experimentais com $P$. aeruginosa. Nos subgrupos do grupo pré-lavagem, nota-se que essa substância de carga invertida teve um comportamento semelhante ao obtido com a Pseudomonas aeruginosa, onde uma redução no número de bactérias aponta para uma possível ação bactericida dessa formulação mesmo antes de ser lavada ou fotoativada, por possivelmente ocasionar a ocorrência de poros no biofilme em questão, levando a morte prévia desses microrganismos.

Desta forma, conclui-se que o procedimento de pré-lavagem da metodologia utilizada na quimioterapia fotodinâmica antimicrobiana (PACT) não mostrou ter interferência nos resultados finais dos experimentos. A redução de microrganismos nos grupos póslavagem só foi observada nos grupos experimentais com a Pseudomonas aeruginosa que receberam os fármacos, apontando para uma ação da droga, e não da metodologia. Não houve diferenças estatísticas significativas entre os grupos experimentais com Staphylococcus aureus, mesmo com a utilização das formulações com Ftalocianina Cloro-Alumínio. Foi possível também observar uma ação bactericida das substâncias testadas, encorajando a realização de análises mais detalhadas para averiguar se esse resultado se mantém com biofilmes mais maduros e se é mais eficaz com substâncias outras associadas à Ftalocianina Cloro-Alumínio.”.

\section{Referências}

Allison RR, Sibata CH. Photofrin photodynamic therapy: $2.0 \mathrm{mg} / \mathrm{kg}$ or not $2.0 \mathrm{mg} / \mathrm{kg}$ that is the question. Photodiagnosis Photodynamic Therapy. 2008; 5(2):112-9. PMid:19356641. http://dx.doi.org/10.1016/j. pdpdt.2008.05.004
Denis TGS, Dai T, Astrakas C, Anderson RR, Hamblin MR. Antimicrobial photoinactivation as an evolving and emerging discovery strategy against infectious disease. Virulence. 2011; 2(6):509-20. PMid:21971183 PMCid:3260545. http://dx.doi.org/10.4161/viru.2.6.17889

Gomes AJ, Lunardi LO, Marchetti JM, Lunard CN, Tedesco AC. Photobiological and ultrastructural studies of nanoparticles of poly(lactic-co-glycolic acid)- containing bactereochlorophy II-a as a photosensitizer useful for PDT treatment. Drug Delivery. 2005; 12(3):159-64. PMid:16025845. http:// dx.doi.org/10.1080/10717540590931846

Karska-Wysocki B, Bazo M, Smoragiewicz W. Antibacterial activity of Lactobacillus acidophilus and Lactobacillus casei against methicillin-resistent Staphylococcus aureus (MRSA). Microbiological Research. 2010; 165:674-86. PMid:20116228. http://dx.doi.org/10.1016/j.micres.2009.11.008

Rajesh S, Koshi E, Koshi P, Mohan A. Antimicrobial photodynamic therapy: an overview. Journal of Indian Society of Periodontology. 2011; 15(4):323-7. PMid:22368354 PMCid:3283927. http://dx.doi.org/10.4103/0972-124X.92563

Ramesh N, Joseph SW, Carr LE, Douglass LW, Wheaton FW. Serial disinfection with heat and chlorine to reduce microorganism populations on poultry transport containers. Journal of Food Protection. 2003; 66(5):793-7. PMid:12747687.

Rosenthal I. Phthalocyanines as photodynamic sensitizers. Photochemistry and Photobiology. 1991; 53(6):859-70. PMid:1886943.

Shieh E, Andrzej P, Wai CM, Lang Q, Crawford RL. Sterilization of Bacillus pumilus spores using supercritical fluid carbon dioxide containing various modifier solutions. Journal of Microbiological Methods. 2009; 76:247-52. PMid:19111835. http://dx.doi.org/10.1016/j. mimet.2008.11.005

Silva JC, Lacava ZGM, Kuckelhaus S, Silva LP, Monteiro LF, Sauro EE, Tedesco AC. Evaluation of the use of low level laser and photosensitizer drugs in healing. Laser in Surgery and Medicine. 2004; 34(5):451-7. PMid:15216540. http://dx.doi.org/10.1002/1sm.20062

Wiedmann MW, Caca, K. General principles of photodynamic therapy (PDT) and gastrointestinal applications. Current Pharmaceutical Biotechnology. 2004; 5(4):397-408. PMid:15320770. http://dx.doi.org/10.2174/1389201043376805

Zhu F, Zheng CJ. Trends in the exploration of anticancer targets and strategies in enhancing the efficacy of drug targeting. Current Molecular Pharmacology. 2008; 1(3):213-32. PMid:20021435. 


\section{Autores}

\section{Jessica Lucia Neves Bastos*}

Programa de Pós-graduação Interunidades Bioengenharia, Instituto de Química de São Carlos - IQSC, Faculdade de Medicina de Ribeirão Preto - FMRP, Escola de Engenharia de São Carlos - EESC, Universidade de São Paulo - USP, Rua Célio Barbosa da Silva, 243, Santa Paula, CEP 13564-060, São Carlos, SP, Brasil.

\section{Márcia Nitschke}

Instituto de Química de São Carlos - IQSC, Universidade de São Paulo - USP, São Carlos, SP, Brasil.

\section{Nivaldo Antonio Parizotto}

Departamento de Fisioterapia (DFisio), Universidade Federal de São Carlos - UFSCar, São Carlos, SP, Brasil.

Programa de Pós-graduação Interunidades Bioengenharia, Instituto de Química de São Carlos - IQSC, Faculdade de Medicina de Ribeirão Preto - FMRP, Escola de Engenharia de São Carlos - EESC, Universidade de São Paulo - USP, São Carlos, SP, Brasil. 